\title{
Lithium-germanium-phosphate glassceramic electrolytes: correlation between the nanocrystallization and electrical studies
}

\author{
Ch. Krishna Kishore Reddy ${ }^{1}$ - G. Suman ${ }^{1}$ - R. Balaji Rao ${ }^{1}$. Naresh Kumar Katari ${ }^{2}$ • \\ M. R. P. Reddy ${ }^{3}$
}

Received: 9 November 2015/ Accepted: 11 January 2016/Published online: 29 January 2016

(c) The Author(s) 2016. This article is published with open access at Springerlink.com

\begin{abstract}
Investigations on the microstructural and electrical properties of a glassceramic system: $(100-x)$ $\left[0.4 \mathrm{Li}_{2} \mathrm{O}-0.1 \mathrm{GeO}_{2}-0.6 \mathrm{P}_{2} \mathrm{O}_{5}\right]+x[20 \mathrm{~h}$ ball milled $\left.\mathrm{Ga}_{2} \mathrm{O}_{3}\right] \quad(0 \leq x \leq 10 \mathrm{~mol} \%$, in the regular steps of $2 \mathrm{~mol} \%$ ) via high-energy ball milling technique are reported. XRD spectra of LGePG glassceramic samples were identified major crystalline phases such as $\mathrm{Li}_{3} \mathrm{Ge}_{2}(-$ $\left.\mathrm{PO}_{4}\right)_{3}$ (NASICON-type phase), $\mathrm{Ga}_{2} \mathrm{Li}_{3}\left(\mathrm{PO}_{3}\right)_{7}$ and $\mathrm{GeO}_{2}$ from the major diffraction peaks. Bulk conductivity of all these samples was measured for the powder-compressed pellets by ac impedance method. The correlation of $\log (\sigma)$ and $M^{\prime \prime}$ peaks suggests the presence of single conduction mechanism in the LGePG glassceramic samples. The results are discussed in the light of degree of crystallization of lithium phosphate glass network.
\end{abstract}

Keywords Glasses $\cdot \mathrm{X}$-ray diffraction $\cdot$ Electrical properties

\section{Introduction}

Recently, solid-state glassceramic electrolytes when precipitated with superionic nanocrystals, they got attracted because of their remarkable electrical conductivity (Al-

R. Balaji Rao

ravuri3091@yahoo.co.in

1 Department of Physics, GITAM University, Hyderabad Campus, Hyderabad, India

2 Department of Chemistry, GITAM University, Hyderabad Campus, Hyderabad, India

3 Center for Materials for Electronics Technology, Hyderabad, India
Hartomy et al. 2013; Fanelli et al. 2011; El-Desoky 2010). Among the oxide and sulfide-based glassceramic electrolytes, the ionic conductivity of sulfide-based compounds is superior over oxide based counter parts. However, sulfides are not chemically stable over longer durations than oxides (Kim et al. 2008, Kim and Jeong 2011). Oxidebased glassceramic electrolytes are highly preferred because they posses excellent chemical and mechanical stability even under heavy loads, nevertheless, their ionic conductivity barely meets the required power densities of the cell (Kim et al. 2008, Kim and Jeong 2011; Hayashi et al. 2012). On the other hand, NASICON-based glassceramic type structure was given top priority as it facilitates the fast diffusion pathways for monovalent ions which is the necessary and sufficient condition for boosting the conductivity at least by two orders (He et al. 2014).

Though, several routes were taking place to enhance ionic conductivity amorphous electrolyte materials, precipitation of nanocrystals in the glass and glassceramic materials via high-energy ball milling was regarded as highly efficient choice, where nanoscaled powders of electrodes directly mixed with electrolytes, leads to reduce the interfacial resistance and also surface modification under room temperature and normal pressure (Kang et al. 2003; Xu and Gao 2004; Lam et al. 2004; Dell et al. 2007; Reddy et al. 2012). Furthermore, it is also to be noted down that the uniform distribution of fine grains of nanocrystalline phases in the glass and glassceramic structure can significantly produce fast diffusion path ways and hence, desirable ionic conductivity is expected to achieve (Dell et al. 2007; Reddy et al. 2012). $\mathrm{Ga}_{2} \mathrm{O}_{3}$ is a good chemically and thermally stable material whose quantum size effects will influence largely on $\mathrm{Li}-\mathrm{Ge}-\mathrm{P}$ network for its high Li ion conductivity, thermal stability, and physical properties (Prasad et al. 2005). On the other 
hand, the role of $\mathrm{GeO}_{2}$ in this glassceramic matrix significantly improves the phase immiscibility during its transition from glass to the glassceramic matrix which is a fundamental property to control the degree of crystallization. In view of this, correlation between the mechanism of crystallization and its electrical transport is worthwhile to discuss for the use in the high-energy density applications (Prasad et al. 2005).

We have already reported in our investigation that the estimated mean sizes for the $20 \mathrm{~h}$ ball milled $\mathrm{Ga}_{2} \mathrm{O}_{3}$ nanocrystallites are obtained by using the Scherrer's formula for half width of the diffraction peaks of the all the in the lithium titatanate phosphate glass ceramic samples vary in between 12 and $17 \mathrm{~nm}$ along with little larger clusters $\sim 20-50 \mathrm{~nm}$ in size for the $20 \mathrm{~h}$ ball mill which was chosen for dispersion in $\mathrm{L}-\mathrm{Ge}-\mathrm{P}$ glassceramic matrix. However, beyond $20 \mathrm{~h}$ the powder gets strained (Reddy et al. 2012).

\section{Experimental}

The glassceramic samples with general formulae: $(100-x) \quad\left[0.4 \mathrm{Li}_{2} \mathrm{O}-0.1 \mathrm{GeO}_{2}-0.6 \mathrm{P}_{2} \mathrm{O}_{5}\right]+x \quad[20 \mathrm{~h}$ ball milled $\left.\mathrm{Ga}_{2} \mathrm{O}_{3}\right] ;(0 \leq x \leq 10 \mathrm{~mol} \%$, in the steps of 2 mol\%) have been synthesized by high-energy ball milling technique, labeled as $\mathrm{LGePG}_{x}$ (where $x$ is the mol\% of $40 \mathrm{~h}$ ball milled $\mathrm{Ga}_{2} \mathrm{O}_{3}$ ) from the mixtures of analytical reagent-grade chemicals of $\mathrm{Li}_{2} \mathrm{CO}_{3}, \mathrm{P}_{2} \mathrm{O}_{5}, \mathrm{GeO}_{2}$ and $\mathrm{Ga}_{2} \mathrm{O}_{3}$. Glassceramic samples are prepared by heating the mechanically milled glasses over their crystallization temperatures. The synthesis procedure to conceive final powders and their green pellets is as published from our laboratory (Reddy et al. 2012). Green pellets thus obtained were sintered over their crystalline temperatures at $2{ }^{\circ} \mathrm{C} /$ min and then cooled down to room temperature in the furnace without any plateau stage. The DTA traces were recorded in the temperature range of 300-1300 $\mathrm{K}$ using analytical grade $\mathrm{Al}_{2} \mathrm{O}_{3}$ as a reference material by using DT-30 Schimadzu thermal analyzer (error $\pm 2 \mathrm{~K}$ ) in flowing nitrogen by heating at $20 \mathrm{~K} / \mathrm{min}$. The degree of crystallization of phases was studied by XRD method using PANanalytical Diffractometer B.V fitted with $\mathrm{Cu}$ target (both $K \alpha_{1}+\alpha_{2}$ wavelengths) and Ni filter at $40 \mathrm{kV}$ and $30 \mathrm{~mA}$ ( $2 \theta$ range). The electrical conductivity studies were carried out using a computer-controlled Solatron 1260 Impedance/Gain phase analyzer with pellet specimens of $10 \mathrm{~mm}$ diameter and about $3 \mathrm{~mm}$ thick. The silver coating was applied on both sides of pellet. Measurements were made conducted in the frequency range of $10-10^{6} \mathrm{~Hz}$ at room temperature and as well as temperatures from 303 to $423 \mathrm{~K}$ with a $10 \mathrm{~K}$ temperature step in dry Ar atmosphere.

\section{Results and discussion}

DTA patterns obtained for all the LGePG glassceramic samples are shown in the Fig. 1. It is to be noted that crystallization phenomenon can be treated as an exothermic process in glasses and glassceramic materials in view of the fact that the free energy of crystalline phase is lower than that of glassy phase. The exothermic peak related to the crystallization temperatures $T_{\mathrm{c}}$ (tangent at the inflexion point) for the possible crystalline phases varies from 877 to $841 \mathrm{~K}$. Where as endothermic related to glass transition $T_{\mathrm{g}}$ (intercept of the base line) changes from 802 to $751 \mathrm{~K}$ from the sample $\mathrm{LGePG}_{0}$ to $\mathrm{LGePG}_{6}$, however, from $\mathrm{LGePG}_{8}$ to $\mathrm{LGePG}_{10}$, the trend is reversed. The glass transition temperature $\left(T_{\mathrm{g}}\right)$ decreases from $\mathrm{LGePG}_{0}$ to $\mathrm{LGePG}_{6}$ which shows their increasing trend of de-polymerization. However, increasing trend in the lattice strain is indicated by the increase in the glass transition temperature $\left(T_{\mathrm{g}}\right)$ from the $\mathrm{LGePG}_{6}(751 \mathrm{~K})$ to $\mathrm{LGePG}_{10}(791 \mathrm{~K})$. Nevertheless, the glass stability parameter $\left(K_{\mathrm{gl}}\right)$ is a good estimate of the glass forming tendency; higher is $K_{\mathrm{gl}}$ value, more stable is the glass and less critical is the quenching rate. It can be calculated from the DTA parameters using the relation

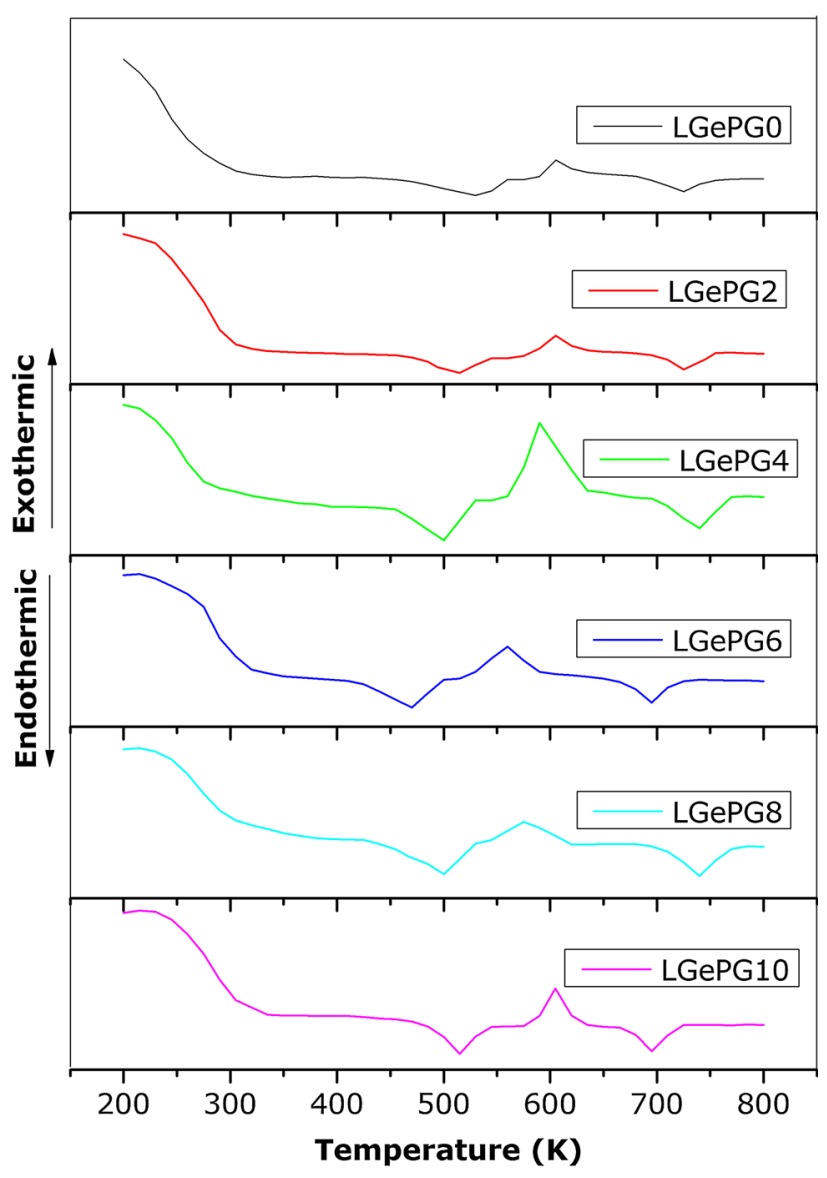

Fig. 1 DTA traces of for all the LGePG glassceramic samples 
Table 1 Summary of DTA data for all the samples of LGePG glassceramic samples

\begin{tabular}{llll}
\hline Sample & $T_{\mathrm{g}}(\mathrm{K})$ & $\Delta T\left(T_{\mathrm{c}}-T_{\mathrm{g}}(\mathrm{K})\right.$ & $\begin{array}{l}K_{\mathrm{gl}}=\left(T_{\mathrm{c}}-T_{\mathrm{g}}\right) / \\
\left(T_{\mathrm{m}}-T_{\mathrm{c}}\right)\end{array}$ \\
\hline $\mathrm{LGePG}_{0}$ & 620 & 40 & 0.620 \\
$\mathrm{LGePG}_{2}$ & 612 & 36 & 0.609 \\
$\mathrm{LGePG}_{4}$ & 601 & 33 & 0.592 \\
$\mathrm{LGePG}_{6}$ & $\mathbf{5 8 3}$ & $\mathbf{2 8}$ & $\mathbf{0 . 5 7 9}$ \\
$\mathrm{LGePG}_{8}$ & 592 & 30 & 0.598 \\
$\mathrm{LGePG}_{10}$ & 608 & 35 & 0.611
\end{tabular}

The best result is set in bold

$\left(K_{\mathrm{gl}}=\left(T_{\mathrm{c}}-T_{\mathrm{g}}\right) /\left(T_{\mathrm{m}}-T_{\mathrm{c}}\right)\right)$ and it should be noted down that for good glass forming systems, the value of $K_{\mathrm{gl}}$ should be greater than or equal to unity (Hruby 1972). The details of DTA parameters for all the LGePG samples are listed in Table 1. The decreasing trend in the value of $K_{\mathrm{gl}}$ from $\mathrm{LGePG}_{0}(0.620)$ to $\mathrm{LGePG}_{6}(0.579)$, denotes the decrease in the degree of de-polymerization, however, from $\mathrm{LGePG}_{8}$ to $\mathrm{LGePG}_{10}, K_{\mathrm{gl}}$ is observed to increase. Though the $K_{\mathrm{gl}}$ of $\mathrm{LGePG}_{6}$ is low compared to other samples of LGePG series, it has become our choice of interest because of two reasons: (a) low glass transition temperature $(751 \mathrm{~K})$ that would exhibit the good electrical properties, (b) optimum degree of crystallization by the precipitation of nanocrystallne phases which would yield correlation between the mean bond strength and cross-link density of the glassceramic networks. Hence, the transformation of amorphous phase (dis-order) into crystalline (order) expected to influence largely on the conduction features as a function of DTA parameters.

Our earlier investigation reported that $\mathrm{Ga}_{2} \mathrm{O}_{3}$ crystallites after $20 \mathrm{~h}$ of milling were precipitated with crystalline phases with optimum crystallization in glassceramic matrix (Reddy et al. 2012). XRD powder diffraction patterns were obtained on all the LGePG glassceramic samples at room temperature is to determine the phase compositions (Fig. 2). Broad crystalline peaks together with other broad and weak clusters of peaks centered at various $2 \theta \mathrm{s}$ in the patterns of all the samples attributed to the secondary phases with variable intensity. The nanocrystalline phases such as $\mathrm{LiGe}_{2}\left(\mathrm{PO}_{4}\right)_{3}$ (NASICON type) and, $\mathrm{Ga}_{2} \mathrm{Li}_{3}\left(\mathrm{PO}_{3}\right)_{7}$ were identified from major diffraction peaks of LGePG samples (Reddy et al. 2015) and these phases were justified by the first and second exothermic peaks in DTA traces (Fig. 1). Nevertheless, there are some weak peaks corresponding to the $\mathrm{GeO}_{2}$ phase and some very weak peaks which are yet to be identified. The NASICON-type phase of $\mathrm{LiGe}_{2}\left(\mathrm{PO}_{4}\right)_{3}$ is observed predominantly as depicted in Fig. 2, and its intensity increases with $\mathrm{Ga}_{2} \mathrm{O}_{3}$ content. Distances between XRD peaks of the samples and the horizontal axis were measured

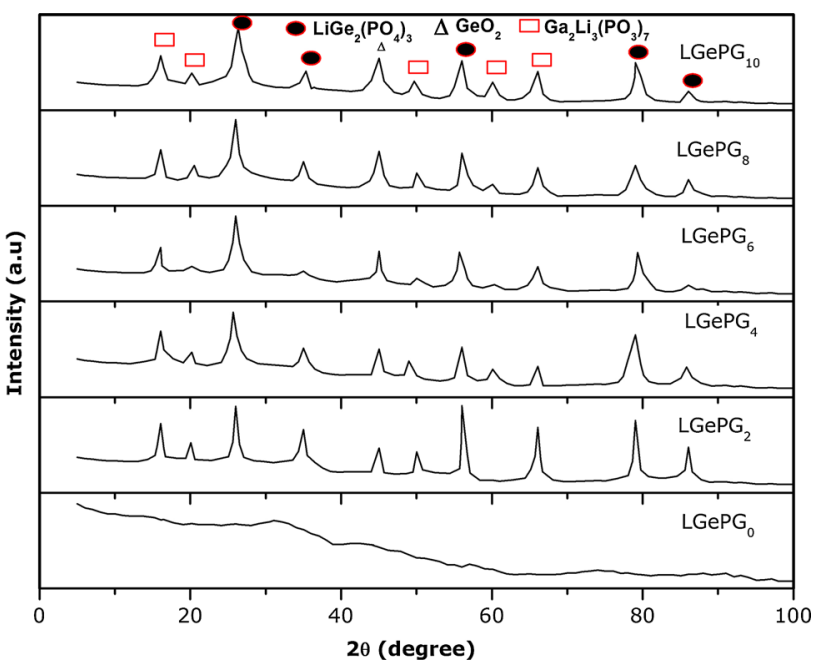

Fig. 2 XRD patterns of all the LGePG glassceramic samples

Table 2 Average percentages of crystallization at various $2 \theta \mathrm{s}$ for LGePG glassceramic samples

\begin{tabular}{ll}
\hline Sample & Avg. percentage crystallization \\
\hline $\mathrm{LGePG}_{0}$ & - \\
$\mathrm{LGePG}_{2}$ & 33.6 \\
$\mathrm{LGePG}_{4}$ & 43.5 \\
$\mathrm{LGePG}_{6}$ & $\mathbf{5 8 . 9}$ \\
$\mathrm{LGePG}_{8}$ & 67.2 \\
$\mathrm{LGePG}_{10}$ & 78.2 \\
\hline
\end{tabular}

The best result is set in bold

at various 20s (JCPDS File, Card no: 80-1922). The volume fraction of crystallization and relative to other for all the LGePG glassceramic samples was obtained by the Ohlberg and Strickler equation (Ohlbeg and Stricklet 1962). The average percentage of crystallization at various $2 \theta \mathrm{s}$ in all the LGePG glassceramic samples is shown in Table 2. The aluminum is absent in this type of phase and there is an every possibility for the partial substitution of ions having similar ionic radii such as $\mathrm{Ge}^{4+}$ by $\mathrm{Al}^{3+}$ during the transformation of glass into glassceramics which induces more $\mathrm{Li}^{+}$ions into the crystal structure, leading to boost the ionic conductivity in the present LGePG glass system. However, the massive crystallization in these glassceramic samples resulting to reduce the conducting features. One more conducting phase $\mathrm{Ga}_{2} \mathrm{Li}_{3}\left(\mathrm{PO}_{3}\right)_{7}$ was also recorded in all the LGePG glassceramic samples which boosts up the electrical conductivity in addition with NASICON-type phase which appears as second exothermic peak in DTA trace (Fig. 1). On the other hand, the $\mathrm{GeO}_{2}$ phase is identified as the most insulating phase, whose intensity is almost constant for all the samples of LGePG glassceramic system (Kim et al. 2006). As shown in Table 2, the secondary $\mathrm{GeO}_{2}$ phase has 
Table 3 Most important crystallographic parameters for crystalline phases for the highest conducting sample $\left(\mathrm{LGePG}_{6}\right)$

\begin{tabular}{llllr}
\hline Phase & \multicolumn{2}{l}{ Unit cell parameters } & & \multicolumn{2}{c}{$\begin{array}{c}\text { Quantitative volume } \\
\text { fraction }(\%)\end{array}$} \\
\cline { 2 - 5 } & $a(\AA)$ & $b(\AA)$ & 2.5681 & 88.93 \\
$\mathrm{LiGe}_{2}\left(\mathrm{PO}_{4}\right)_{3}$ & 8.2643 & 8.2645 & 7.1230 & 8.49 \\
$\mathrm{Ga}_{2} \mathrm{Li}_{3}\left(\mathrm{PO}_{3}\right)_{7}$ & 7.6503 & 7.6503 & 5.5780 & 2.58 \\
$\mathrm{GeO}_{2}$ & 5.0012 & 5.0012 & \\
\hline
\end{tabular}
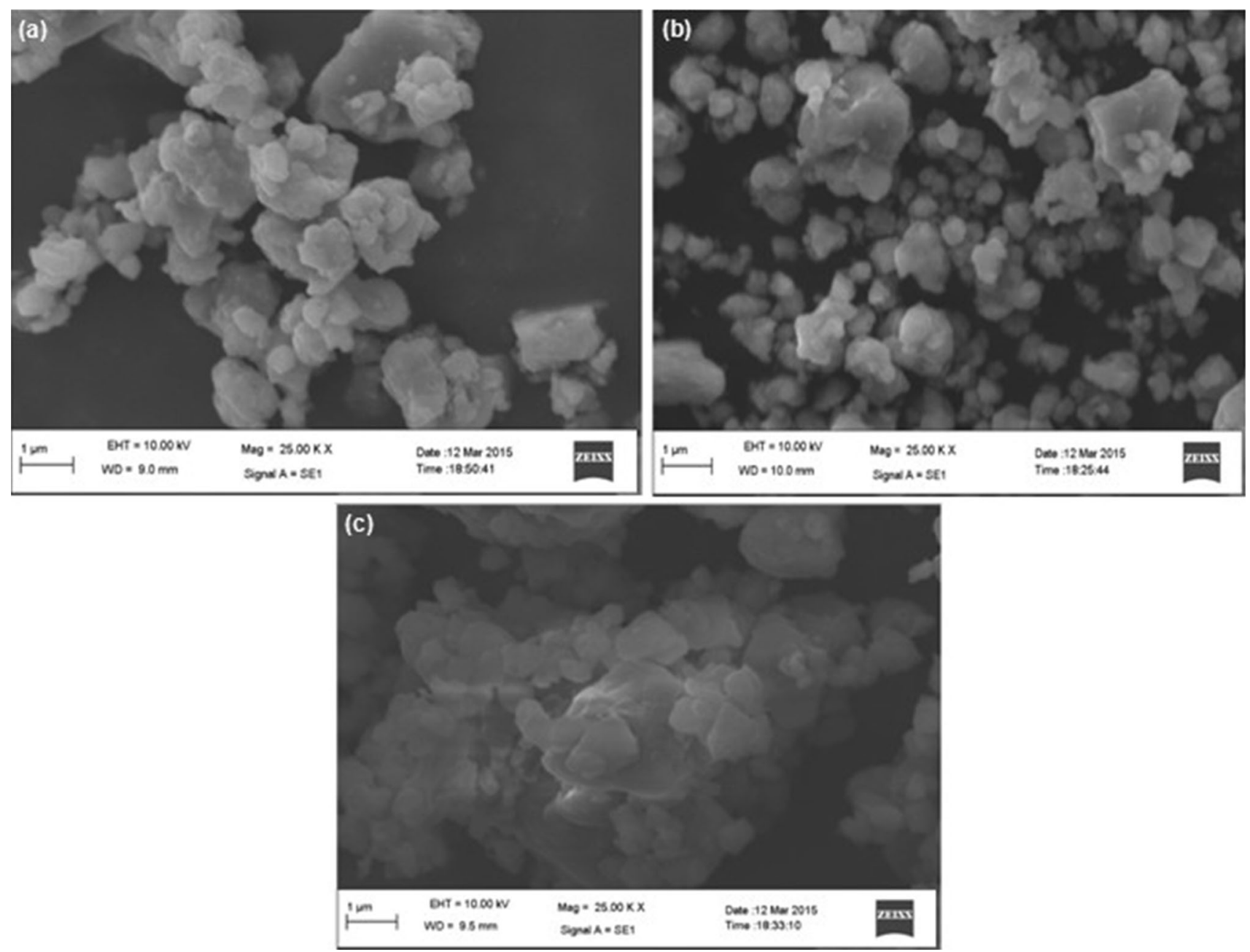

Fig. 3 SEM images of some a $\mathrm{LGePG}_{2}, \mathbf{b} \mathrm{LGePG}_{6}$, $\mathbf{L} \mathrm{LGePG}_{10}$ glassceramic samples

appeared with small volume fraction $(2.58 \%)$ out of the average crystallization percentage of NASICON-type phase in $\mathrm{LGePG}_{6}$ sample (Table 3) which does not affect much on the overall mechanism of crystallization of glass. The analysis reflects that the predominant NASICON-type phase $\left(\mathrm{LiGe}_{2}\left(\mathrm{PO}_{4}\right)_{3}\right)$ which has been characterized as rhombohedral crystal system with a unit cell of dimensions $a=8.2643 \AA, \quad b=8.2645 \AA, c=2.5681 \AA$ and $\beta=$ $98.99^{\circ}$, which is in agreement with the reported data (JCPDS card) and space group R3c. However, correlation between the quantitative volume fraction of crystalline phases (Table 3) and their electrical features of the LGePG glassceramic samples will be discussed in the next section.

SEM images of some samples are crucial to analyse crystallization behavior by considering the phase and microstructural details (Fig. 3). It can be seen from the Fig. 3, that crystalline phase appears with white region where as residual glass phase appears with black region. Figure 3a, c shows the presence of agglomerated grain like crystallites (170-300 nm) of major crystalline phases 
$\left[\mathrm{LiGe}_{2}\left(\mathrm{PO}_{4}\right)_{3}\right.$ (NASICON type), and $\left.\mathrm{Ga}_{2} \mathrm{Li}_{3}\left(\mathrm{PO}_{3}\right)_{7}\right]$ precipitated along the grain boundaries. SEM image of $\mathrm{LGePG}_{6}$ glassceramic sample (Fig. 3b) revealed the presence of interconnected fine and uniform grain crystallites $(110-170 \mathrm{~nm})$ of all the as mentioned major crystalline phases which are uniformly dispersed in the glass matrix and separated by well-developed grain boundaries throughout the micrograph. XRD pattern (Fig. 2) justified these grain-like crystallites belong to the major crystalline phases $\left[\mathrm{LiGe}_{2}\left(\mathrm{PO}_{4}\right)_{3}\right.$ (NASICON type), and $\mathrm{Ga}_{2} \mathrm{Li}_{3}(-$ $\left.\mathrm{PO}_{3}\right)_{7}$ ]. Nevertheless, it can be seen from Fig. 3b that the crystal growth of crystallites is optimum and distributed by connective tissues of the $\mathrm{LGePG}_{6}$ glassceramic matrix among all the samples under investigation. On the other hand, crystal growth of the crystallites is not perfect and uniform for rest of all other samples as synthesized. To get better conducting features via the presence of the ionically conductive, interfacial region between the glassy matrix and devitrified crystalline grain, further investigations require on the heat treatment schedule around the glass transition temperature $\left(T_{\mathrm{c}}\right)$ of these LGePG glassceramic samples.

The electrical properties of as synthesized glass and glassceramic samples were monitored using impedance spectroscopy (Kupracz et al. 2015). This technique is relatively powerful to investigate the dynamics of mobile charges in the bulk or interfacial regions of any kind of materials which operates an alternating current with variable frequency. The impedance data obtained were fitted to nonlinear least-square method. Here, the electrical properties can be associated to a parallel resistance and capacitance circuit corresponding to equivalent to the individual component of the materials (i.e., bulk and grain boundary) represents a semicircle and therefore bulk response of the sample is detected. Hence, the bulk conductivity may be evaluated for all the LGePG glassceramic samples from the impedance spectrum using the relation

$\sigma_{\mathrm{b}}=t /(R \cdot A)$

where $R$ is the bulk resistance which was determined from the intersection of the semicircle with the real axis of the impedance $Z^{\prime} ; t$ the thickness, and $A$ the surface area of the sample and is achieved to be highest for $\mathrm{LGePG}_{6}$ sample $\left(\sigma=8.31 \times 10^{-04} \mathrm{~S} / \mathrm{cm}\right)$ at $303 \mathrm{~K}$ (Fig. 4). Compositional dependence of glass stability parameter $\left(K_{\mathrm{gl}}\right)$ and bulk conductivity $\left(\sigma_{\mathrm{b}}\right)$ for all the LGePG glassceramic samples are depicted in Fig. 4. The lowest value of glass stability parameter $\left(K_{\mathrm{gl}}\right)$ for the highest conducting $\mathrm{LGePG}_{6}$ sample indicates that optimum degree of its crystallization achieved by the precipitation of nanocrystalline phases boosting the conductivity features as justified by XRD patterns and SEM images (Milankovic et al. 1997; Garbarczyk et al. 2006).

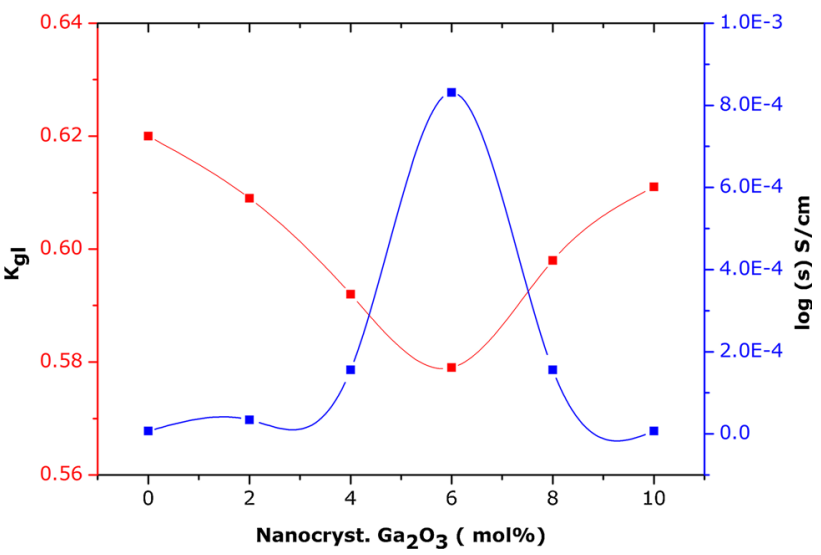

Fig. 4 Variation of glass forming ability parameter $\left(K_{\mathrm{gl}}\right)$ and $\log (\sigma)$ (at $303 \mathrm{~K}$ ) with nanocrystal $\mathrm{Ga}_{2} \mathrm{O}_{3}(\mathrm{~mol} \%$ ) for all the $\mathrm{LGePG}$ samples

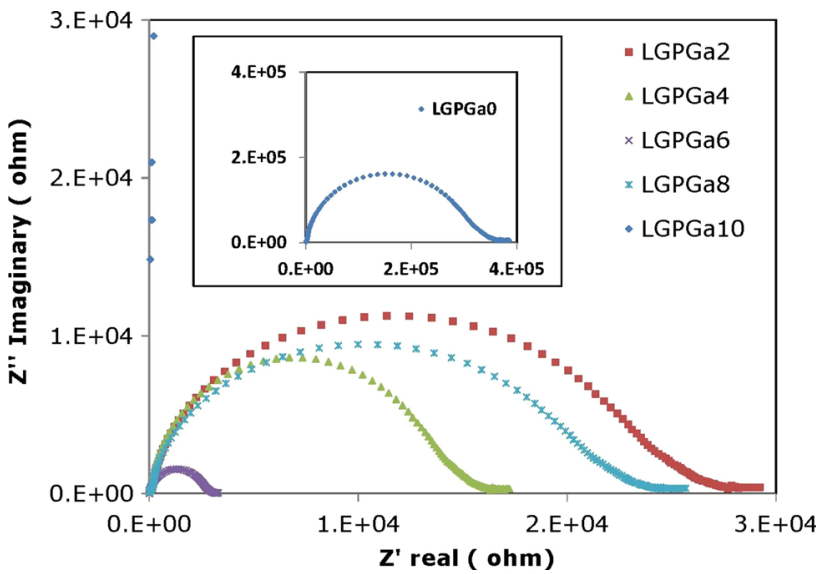

Fig. 5 Complex impedance spectra $\left(Z^{\prime \prime}\right.$ vs $\left.Z^{\prime}\right)$ for all the LGePG glassceramic samples at $303 \mathrm{~K}$

The Nyquist plots between ( $Z^{\prime \prime}$ vs $\left.Z^{\prime}\right)$ for all the LGePG glassceramic samples measured at $303 \mathrm{~K}$ and for highest conducting sample $\mathrm{LGePG}_{6}$ at different temperatures are shown in Figs. 5 and 6. The impedance spectrum was found to exhibit single semicircular arc which shows that the electrical properties of present samples arises due to bulk effects. Bulk conductivity of all the glassceramic samples at different temperatures (303-423 K) is obtained by using the resistance $(R)$ obtained from the analyzed impedance data and pellet dimensions. It can be seen that increase in temperature caused the impedance semicircles to be shifted to lower and lower $Z^{\prime}$ values which indicates the decrease in the resistive property of the material (Fig. 6).

The conductivity data are fitted to the Arrhenius equation

$\sigma_{\mathrm{dc}}=\sigma_{0} \exp \left(-E_{a \sigma} / k T\right)$

$\sigma_{0}$ is the pre exponential factor and $E_{a \sigma}, k$ and $T$ are the activation energy for the conduction, Boltzman's constant 


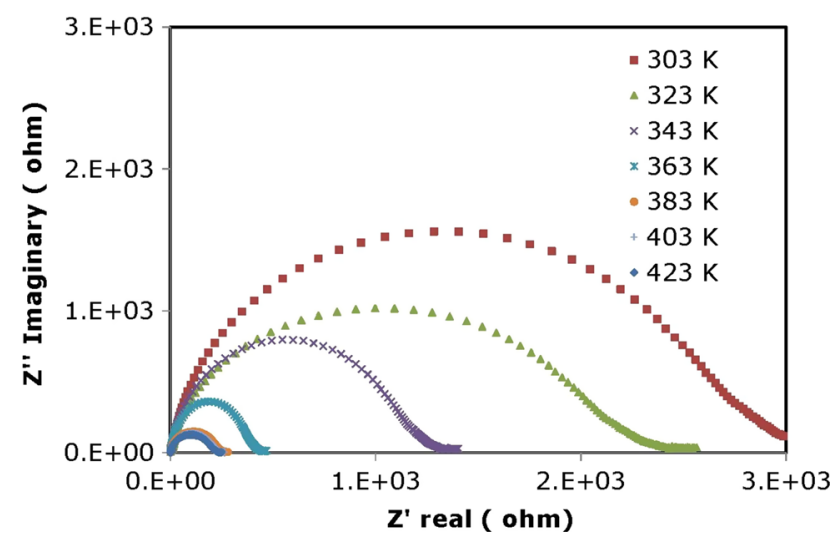

Fig. 6 Impedance spectra $\left(Z^{\prime \prime}\right.$ vs $\left.Z^{\prime}\right)$ for the highest conducting sample $\mathrm{LGePG}_{6}$ at different temperatures (303-423 K)

$\left(1.3806 \times 10^{-22} \mathrm{~J} / \mathrm{K}\right)$ and absolute temperature, respectively. The activation energy for conduction $\left(E_{a \sigma}\right)$ was calculated from the slope of the straight lines obtained when the data is plotted against 1000/T of all the glassceramic samples. The slope is calculated as follows. $\left(-E_{a \sigma} / k T\right)$ is the slope and Eq. (2) can be written as

$\ln (\sigma)=\ln (A)$ slope $\left(\frac{1}{T}\right)$

and the value of slope can be calculated from the linear graph of $\ln (\sigma)$ vs $\frac{1}{T}$ as follows

Slope $=\frac{\Delta \ln (\sigma)}{\Delta \frac{1}{T}}$

The activation energy for conduction $\left(E_{a \sigma}\right)$ is now calculated as $E_{a \sigma}=-k \times$ slope. The slope being negative, a positive value of $E_{a \sigma}$ is obtained.

The compositional dependence of activation energy for conduction $\left(E_{a \sigma}\right)$ for all the LGePG glassceramic samples at $303 \mathrm{~K}$ is shown in the Fig. 7. It is observed that the

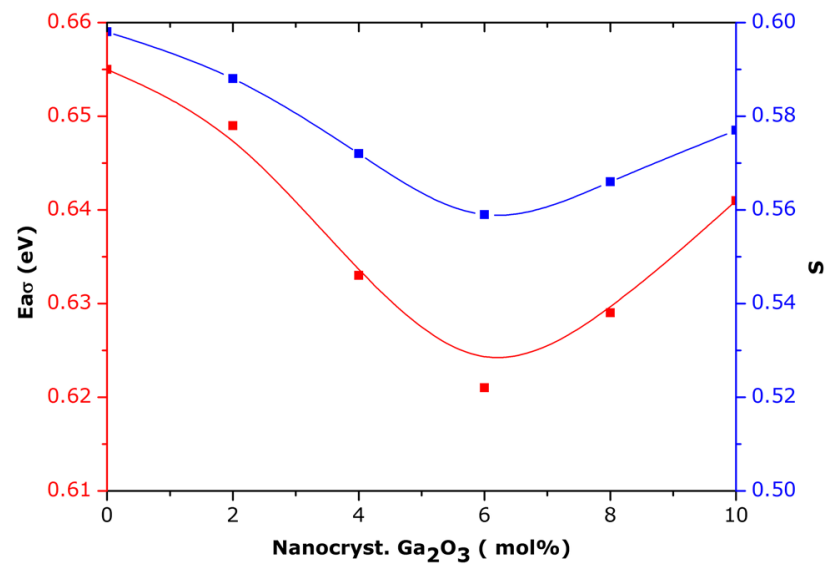

Fig. 7 Compositional dependence of activation energy for conduction $\left(E_{a \sigma}\right)$ and characteristic parameter $(s)$ measured at $303 \mathrm{~K}$ activation energy is found to be the lowest for the highest conducting sample $\mathrm{LGePG}_{6}$ (Fig. 7) and it does not show the nonlinear behavior of conductivity which reveals that the variation of mobile $\mathrm{Li}^{+}$ion conductivity is directly related to the percentage of crystallization (Panmand et al. 2010; Raghavan and Rao 1996; Xiaoxiong et al. 2006). The same has been justified by the intensity and broadening of XRD peaks of $\mathrm{LGePG}_{6}$ among all the samples under investigation with optimum crystallization (58.9\%). Hence, the increased mobility of $\mathrm{Li}^{+}$ions in addition to the percentage of crystallization plays a vital role in boosting the conductivity of the LGePG series of samples (Heitjansa et al. 2008; Garbarczyk et al. 2006).

The frequency-dependent electrical conductivity fulfills the power-law equation

$\sigma_{\mathrm{ac}}=\sigma_{o}+A \omega^{s}$

where characteristic parameter ' $s$ ' lies in between zero and one and decreases slightly with increasing temperature. In general, the low-frequency part of the conductivity is frequency independent and the frequency-independent conductivity $\left(\sigma_{o}\right)$ is obtained by extrapolation of the conductivity approaches to the frequency as zero. Conductivity exhibits the dispersion at the high-frequency region and increases in a power-law fashion (Nobre and Lafendri 2001). AC conductivity plots as a function of frequency for all the LGePG samples at $303 \mathrm{~K}$ are shown in Fig. 8. It is to be noted down that change in the slope of ac conductivity with frequency concludes domination of grain resistance over grain boundary resistance for a particular temperature (Sambasiva Rao et al. 2008). The small deviation from $\sigma_{\mathrm{dc}}$ in the frequency-independent part of the conductivity reflects the influence of electrode polarization in the glassceramic samples. Critical frequency is frequency $\left(\omega_{p}=f_{o}\right)$, at which the conductivity deviates from the frequency-independent part. The shift in the critical frequency towards higher frequency side on increasing

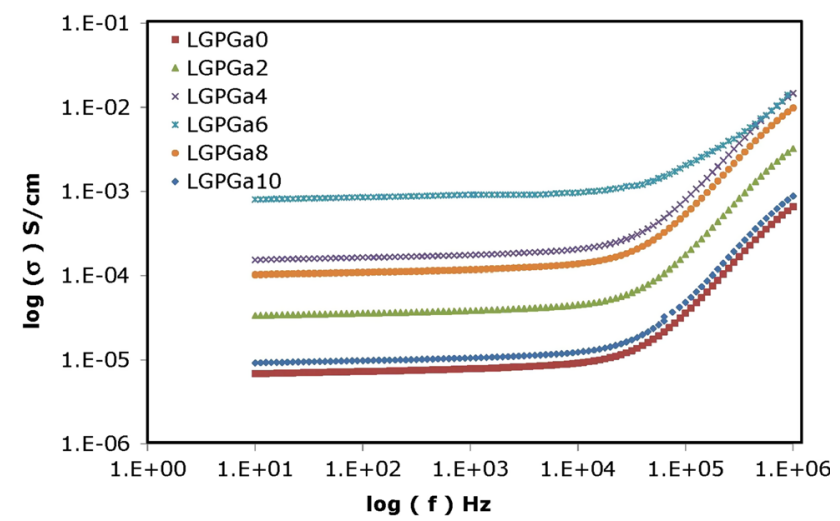

Fig. $8 \log (\sigma)$ versus $\log (f)$ plots for all the LGePG glassceramic samples measured at $303 \mathrm{~K}$ 


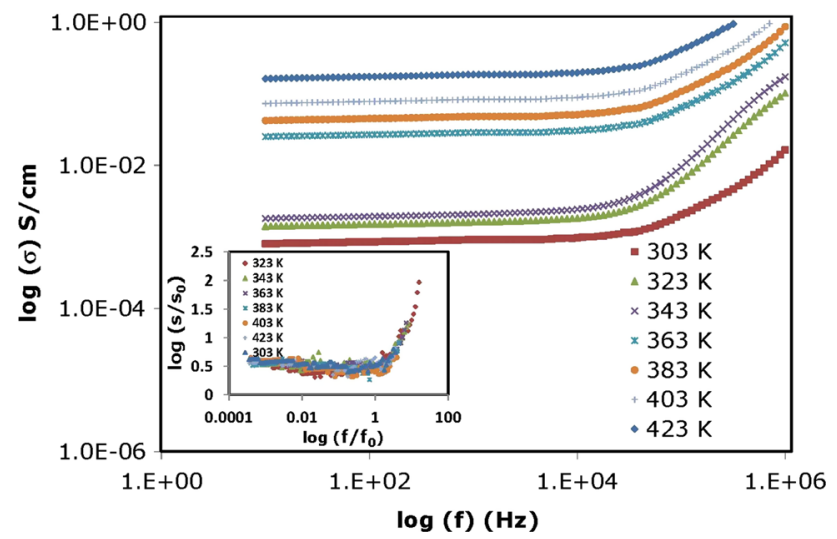

Fig. $9 \log (\sigma)$ versus $\log (f)$ plots for highest conducting sample $\mathrm{LGePG}_{6}$ at different temperatures (303-423 K). Inset shows normalized plots of electrical conductivity for highest conducting sample $\mathrm{LGePG}_{6}$ at different temperatures (303-423 K)

temperature is a little more obvious for the ac conductivity of $\mathrm{LGePG}_{6}$ at different temperatures (Fig. 9). Nevertheless, the relation between frequency-independent conductivity $\sigma_{0}$ and the critical frequency $\left(f_{o}\right)$ can be represented by the following equation:

$\sigma_{o}=K f_{o}$

where $K=\left(N e^{2} a^{2} / k T\right) v c(1-c)$, is the empirical constant that depends on the concentration of mobile ions, temperature and the conduction mechanism (Jain et al. 1993). In the equation for $K, v$ is the geometrical factor which includes the correlated factor, $c$ is the concentration of mobile ions on $N$ equivalent lattices per unit volume, $a$ is the hopping distance, $e$ is the electronic charge, $T$ is absolute temperature and $k$ is Boltzman's constant. The relaxation effects begin to appear at the critical frequency $\left(f_{o}\right)$, which moves towards the higher frequency with an increase in the temperature of the measurement. Further, it is observed that the critical frequency $\left(f_{o}\right)$ is thermally activated with the same activation energy as that of the conductivity $\sigma_{0} T$ (Verhoef and den Hartog 1994).

Compositional dependence of characteristic parameter $(s)$ is known to be material dependent and its value is observed to be the lowest for highest conducting sample $\mathrm{LGePG}_{6}$ (Fig. 7). A summary of the electrical conductivity, activation energy and characteristic parameters is given in Table 4. The frequency-independent part and dependent parts of the conductivity may be explained by long-range transport of $\mathrm{Li}^{+}$ions and diffusion controlled relaxation model (Elliot and Owens 1994).

To explore the further information about the dependence of the ion transport on the composition, temperature, structure, and also on the concentration of the charge carriers, the ac conductivity data obtained at various temperatures for $\mathrm{LGePG}_{6}$ at different temperatures have been scaled and are presented in the inset of Fig. 9 (Karmakar et al. 2009). Perfect overlapping of normalized imaginary part of AC conductivity plots of LGePG samples suggested the conduction transport mechanism to be temperature independent. The contribution of highly conductive phases such as NASICONtype phase of $\mathrm{LiGe}_{2}\left(\mathrm{PO}_{4}\right)_{3}$ in addition with another conducting phase $\mathrm{Ga}_{2} \mathrm{Li}_{3}\left(\mathrm{PO}_{3}\right)_{7}$ is boosting the ac conductivity from $\mathrm{LGePG}_{0}$ to $\mathrm{LGePG}_{6}$ (Kun et al. 2011). On the other hand, the highest conductivity is achieved to be $\left(\sigma=8.31 \times 10^{-04} \mathrm{~S} / \mathrm{cm}\right)$ for $\mathrm{LGePG}_{6}$ sample which is expected due to the optimum percentage of crystallization $58.9 \%$ (Table 2) and the presence of uniform distribution of conducting crystalline phases. However, the massive crystallization results to decrease the conductivity from $\mathrm{LGePG}_{8}$ to $\mathrm{LGePG}_{10}$ (Garbarczyk et al. 2006). In this process, we have monitored variation of imaginary permittivity $\left(\varepsilon^{\prime \prime}\right)$ with frequency, where the imaginary part $\varepsilon^{\prime \prime}$ is exceeded by the dc conductivity and will not be discussed further and hence, the modulus formalism was used for the further analysis.

Electrical modulus formulation is a convenient tool to explore electrical transport phenomenon of the material. Also, it pacifies the noise of extrinsic relaxation often used in the analysis of electrode polarization and bulk phenomena such as average conductivity relaxation times $\tau_{\sigma}$ of ionically conducting glasses (Mc Crum et al. 1967; Moynihan 1994; Moynihan et al. 1973).

It is speculated that the simultaneous application of both impedance ( $Z^{\prime \prime}$ vs $Z^{\prime}$ ) and modulus $\left(M^{\prime \prime}\right.$ vs $\left.M^{\prime}\right)$ spectroscopy

Table 4 Summary of conductivity $(\sigma)$, activation energy $\left(E_{a \sigma}\right.$ and $\left.E_{a \tau}\right)$ characteristic parameter $(s)$ and stretched exponent $(\beta)$ and relaxation time $(\tau)$ of LGePG glassceramic samples

\begin{tabular}{llllrrr}
\hline Glass & $\sigma(303 \mathrm{~K}) \mathrm{S} / \mathrm{cm}$ & $E_{a \sigma}(\mathrm{eV})$ & $s(303 \mathrm{~K})$ & $E_{a \tau}(\mathrm{eV})$ & $\beta(303 \mathrm{~K})$ & $\tau\left(10^{-6} \mathrm{~s}\right) 303 \mathrm{~K}$ \\
\hline $\mathrm{LGePG}_{0}$ & $(6.96 \pm 0.81) \mathrm{E}-06$ & $0.655 \pm 0.007$ & 0.598 & $0.648 \pm 0.005$ & 0.551 & 2.52 \\
$\mathrm{LGePG}_{2}$ & $(3.43 \pm 0.74) \mathrm{E}-05$ & $0.649 \pm 0.005$ & 0.588 & $0.64 \pm 0.006$ & 0.539 & 2.21 \\
$\mathrm{LGePG}_{4}$ & $(1.56 \pm 0.89) \mathrm{E}-04$ & $0.633 \pm 0.006$ & 0.572 & $0.632 \pm 0.004$ & 0.522 & 1.78 \\
$\mathrm{LGePG}_{6}$ & $\mathbf{( 8 . 3 1} \pm \mathbf{0 . 7 9}) \mathrm{E}-\mathbf{0 4}$ & $\mathbf{0 . 6 2 1} \pm \mathbf{0 . 0 0 8}$ & $\mathbf{0 . 5 5 9}$ & $\mathbf{0 . 6 1 8} \pm \mathbf{0 . 0 0 1}$ & $\mathbf{0 . 5 1 8}$ & $\mathbf{1 . 5 7}$ \\
$\mathrm{LGePG}_{8}$ & $(1.56 \pm 0.91) \mathrm{E}-04$ & $0.629 \pm 0.003$ & 0.566 & $0.622 \pm 0.006$ & 0.529 & 1.42 \\
$\mathrm{LGePG}_{10}$ & $(6.96 \pm 0.93) \mathrm{E}-06$ & $0.641 \pm 0.007$ & 0.577 & $0.644 \pm 0.003$ & 0.534 & 1.26 \\
\hline
\end{tabular}

The best result is set in bold 


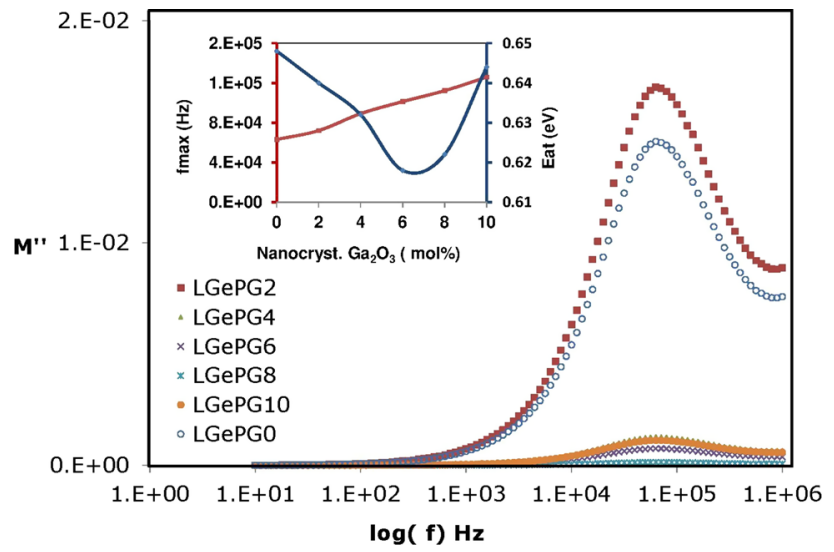

Fig. 10 Electric modulus $\left(M^{\prime \prime}\right)$ versus $\log (f)$ plots for all the LGePG glassceramic samples measured at $303 \mathrm{~K}$. Inset shows the compositional dependence of variation of activation energy for relaxation $\left(E_{a \tau}\right)$ and $f_{\max }$ measured at $303 \mathrm{~K}$

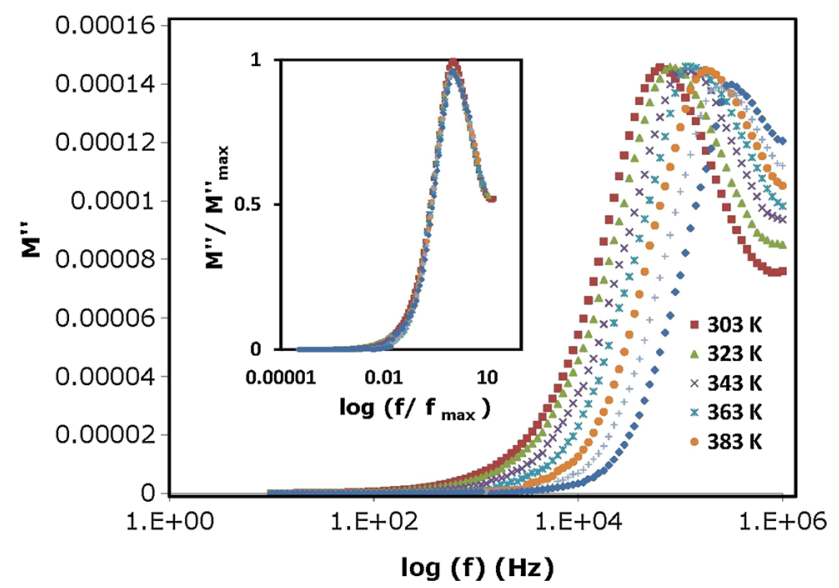

Fig. 11 Electric modulus $\left(M^{\prime \prime}\right)$ versus $\log (f)$ plots the highest conducting glass ceramic sample $\mathrm{LGePG}_{6}$ measured at at different temperatures (303-423 K). Normalized plots of electric modulus of the highest conducting sample $\left(\mathrm{LGePG}_{6}\right)$ at different temperatures $303-423 \mathrm{~K}$

would deal to rationalize the dielectric properties (Sinclair and West 1989, 1997). In view of technological importance, we have analysed both electrical conductivity and modulus formalisms simultaneously, in this investigation. Figures 10 and 11 show the frequency dependence of imaginary part of electric modulus $M^{\prime \prime}$ for all the LGePG samples at $303 \mathrm{~K}$ and for highest conducting sample $\mathrm{LGePG}_{6}$ at different temperatures $(303-423 \mathrm{~K})$. The $M^{\prime \prime}$ value is observed to be constant $\left(M^{\prime \prime}{ }_{\max }\right)$ at a relaxation frequency $\left(f_{\max }\right)$ and the peak $M^{\prime \prime}{ }_{\text {max }}$ symmetrically shifts towards higher frequencies with increasing temperatures (Fig. 11). This behavior suggests that the dielectric relaxation is not the usual thermally activated type in which hopping mechanism of charge carriers dominates

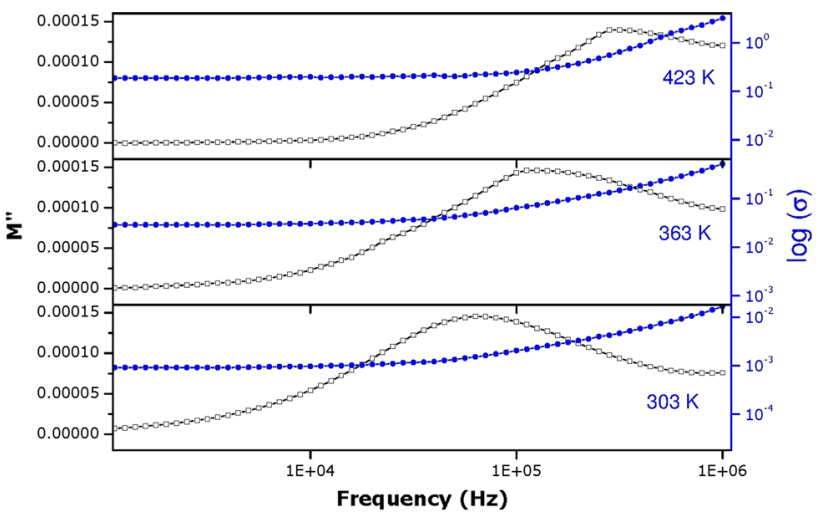

Fig. 12 Frequency $(\log f)$ vs bulk conductivity $(\log \sigma)$ and imaginary part of electric modulus $\left(M^{\prime \prime}\right)$ at three different temperatures $(323,363$ and $423 \mathrm{~K}$ ) of $\mathrm{LGePG}_{6}$

intrinsically. From Fig. 10, the relaxation frequency $\left(f_{\max }\right)$ corresponding to the maximum in $M^{\prime \prime}$ curves and the relaxation time $\tau$, calculated using the relation $\tau=1 / 2 \pi$ $f_{\max }$ at different temperatures can be obtained and presented in Table 4. Nevertheless, the activation energy for the conductivity relaxation $E_{a \tau}$ for all the LGePG samples was calculated from the relaxation time plots and the values of $E_{a \tau}$ and $E_{a \sigma}$ are in good agreement with each other (Table 4) which suggest that the ionic-hopping mechanism responsible for the relaxation is the same as that for the conductivity (Chowdari et al. 1990). In principle, full width half maximum $(\beta)$ can be calculated by the width at the half maxima for any bell shaped curve and the same method was adopted for all the frequency-dependent electrical modulus curves (Fig. 10). The full width half maximum $(\beta)$ and characteristic relaxation time $(\tau)$ of $M^{\prime \prime}$ peaks are given in Table 4. The value of $\beta$ is lowest for the highest conducting sample $\mathrm{LGePG}_{6}$, which justifies its optimum percentage of crystallization as supported in the XRD analysis leading to modify the conductivity in the neighborhood of conduction path. The overlap of critical frequency $\left(f_{\mathrm{o}}\right)$ of $\log (\sigma)$ peaks and relaxation frequency of and $M^{\prime \prime}$ peaks for the highest conducting sample $\mathrm{LGePG}_{6}$ at different temperatures $(323,363$ and $423 \mathrm{~K}$ ) have been demonstrated to be a result from the same mechanism and this result is further confirmed that the two processes are closely correlated with each other (Fig. 12). As the temperature increases, the same corresponding peak shifts to a higher frequency but they present the same characteristic relaxation time at specific temperatures. Nevertheless, the peak in $\log (\sigma)$ is slightly shifted to a higher frequency with respect to the $M^{\prime \prime}$ peak position in all LGePG samples which suggests the presence of possibly more than one mechanism but this contribution does not influence the overall conductivity response that much as it was determined that the activation energies calculated from the conductivity curves and those of the relaxation were 
essentially the same. This is supported by master curves in the normalized plots of electric modulus spectra (inset of Fig. 11), which suggests that the dynamical relaxation processes in the LGePG samples is temperature independent. The $\beta$ values show that the conductivity relaxation is to be highly nonexponential with increasing temperature (Table 4).

\section{Conclusions}

The lowest value of $K_{\mathrm{gl}}$ for the glassceramic sample $\mathrm{LGePG}_{6}$ (0.517), denotes the decrease in the degree of de-polymerization which possesses fast diffusion pathways, leading to achieve good compatibility between electrodes. XRD patterns pointed out that the $\mathrm{LGePG}_{6}$ sample exhibits the optimum crystallization of nanocrystalline phases such as $\mathrm{LiGe}_{2}\left(\mathrm{PO}_{4}\right)_{3}$ (NASICON type), $\mathrm{Ga}_{2} \mathrm{Li}_{3}\left(\mathrm{PO}_{3}\right)_{7}$ from major diffraction peaks. SEM pictures revealed that $\mathrm{LGePG}_{6}$ glassceramic sample is observed to be interconnected fine and uniform crystallites of major crystalline phases $\left(\mathrm{LiGe}_{2}\left(\mathrm{PO}_{4}\right)_{3}\right.$ (NASI$\mathrm{CON}$ type), $\left.\mathrm{Ga}_{2} \mathrm{Li}_{3}\left(\mathrm{PO}_{3}\right) 7\right)$ which are uniformly dispersed in the glass matrix and separated by well-developed grain boundaries which is justified by XRD pattern. The bulk conductivity is achieved to be the highest for $\mathrm{LGePG}_{6}$ sample $\left(8.31 \times 10^{-04} \mathrm{~S} / \mathrm{cm}\right)$. The $M^{\prime \prime}$ spectra shows non-Debye type relaxation and shift to higher frequency side for the sample $\mathrm{LGePG}_{6}$ with the highest conductivity due to the increase of mobile charge carriers and the same would be applicable for all the other samples under investigation. The modulus scaling spectra show that the dynamical relaxation processes is temperature independent for a particular composition. The $\beta$ exponent value indicates that the conductivity relaxation is highly nonexponential (Table 4).

Open Access This article is distributed under the terms of the Creative Commons Attribution 4.0 International License (http:// creativecommons.org/licenses/by/4.0/), which permits unrestricted use, distribution, and reproduction in any medium, provided you give appropriate credit to the original author(s) and the source, provide a link to the Creative Commons license, and indicate if changes were made.

\section{References}

Al-Hartomy OA, Al-Ghamdi AA, El-Tantawy F, El-Desoky MM (2013) Effect of nanocrystallization on the structural and electrical conductivity enhancement of vanadium-based glasses. J Mater Sci 48:3067-3074

Chowdari BVR, Krishnan RG, Ghosh SH, Tan KL (1990) Thermal, electrical and structural characterization of $\mathrm{Li}_{2} \mathrm{O} \cdot \mathrm{P}_{2} \mathrm{O}_{5} \cdot \mathrm{MoO}_{3}$ glasses. Solid State Ionics 40-41(2):684-688

Dell LAO, Savin SLO, Chadwick AV, Smith ME (2007) Multi nuclear MAS NMR investigation of sol-gel and ball milled nanocrystalline $\mathrm{Ga}_{2} \mathrm{O}_{3}$. Appl Mag Reson 32:527-546
El-Desoky MM (2010) Gaint electrical conductivity enhancement in $\mathrm{BaO}-\mathrm{V}_{2} \mathrm{O}_{5}-\mathrm{Bi}_{2} \mathrm{O}_{3}$ glass by nanocrystallization. Mater Chem Phys 119:389-394

Elliot SR, Owens AP (1994) Frequency-dependent conductivity in ionically and electronically conducting amorphous solids. Solid State Ionics 70:27

Fanelli E, Pernice P, Xiao M, Sigaev VN (2011) Crystallization behaviour and nanostructuring in alkali niobiosilicate glasses. J Mater Sci Technol 27(2):189-192

Garbarczyk JE, Jozwiak P, Wasiucionek M, Nowinski JL (2006) Effect of nanocrystallization on the electronic conductivity of vanadate-phosphate glasses. Solid State Ionics 177:2585-2588

Hayashi A, Noi K, Sakuda A, Tatsumisago M (2012) Superionic glassceramic electrolytes for room-temperature rechargeable sodium batteries. Nat Commun 3:856-860

He K, Zu C, Wang Y, Han B, Yin X, Zhao H (2014) Stability of lithium ion conductor NASICON structure glass ceramic in acid and alkaline aqueous solution. Solid State Ionics 254:78-81

Heitjansa P, Tobschallb E, Wilkening M (2008) Ion transport and diffusion in nanocrystalline and glassy ceramics Eur. Phys J Spec Topics 161:97

Hruby A (1972) Evalution of glass-forming tendency by means of DTA. Czech J Phys B 22(11):1187-1193

Jain H, Kanert O (1993) In: Spaeth JM (eds) Proceedings of the XII international conference on defects in insulting materials, vol 1. World Scientific Co, p 274

Kang D, Han M, Lee SG (2003) Dielectric and pyroelectric properties of barium strontium calcium titanate ceramics. J Eur Cerm Soc 23(3):515-518

Karmakar A, Majumdar S, Giri S (2009) Polaron relaxation and hopping conductivity in $\mathrm{LaMn}_{1-\mathrm{x}} \mathrm{Fe}_{\mathrm{x}} \mathrm{O}_{3}$. Phys Rev B 79:094406/ $1-094406 / 7$

Kim H-S, Jeong C-S (2011) Electrochemical properties of binary electrolytes for lithium-sulfur batteries. Bull Korean Chem Soc 32:3682-3686

Kim Y, Saienga J, Martin SW (2006) Anomalous ionic conductivity increase in $\mathrm{Li}_{2} \mathrm{~S}-\mathrm{GeS}_{2}-\mathrm{GeO}_{2}$ glasses. $\mathrm{J}$ Phys Chem $\mathrm{B}$ 110(33):16318-16325

Kim Y, Hwang H, Lawler K, Martin SW, Cho J (2008) Electrochemical behavior of $\mathrm{Ge}$ and $\mathrm{GeX}_{2}(\mathrm{X}=\mathrm{O}, \mathrm{S})$ glasses: improved reversibility of the reaction of $\mathrm{Li}$ with $\mathrm{Ge}$ in a sulfide medium. Electrochim Acta 53:5058-5064

Kun HE, Yan-Hang W, Cheng-Kui Z, Yong-Hua L, Hui Feng Z, Bin $\mathrm{H}$, Jiang $\mathrm{C}$ (2011) Microstrucutre and Ionic conductivity of $\mathrm{Li}_{2} \mathrm{O}-\mathrm{Al}_{2} \mathrm{O}_{3}-\mathrm{GeO}_{2}-\mathrm{P}_{2} \mathrm{O}_{5}$ glassceramics. Chin $\mathrm{J}$ Inorg Chem 27(12):2484-2488

Kupracz P, Karczewski J, Prześniak-Welenc M, Szreder NA, Winiarski MJ, Klimczuk T, Barczy'nski RJ (2015) Micrsostructure and electrical properties of manganese borosilicate glasses. Non-Cryst Solids 423-424:68-75

Lam HM, Hong MH, Yuan S, Chong C (2004) Growth of $\beta-\mathrm{Ga}_{2} \mathrm{O}_{3}$ nanoparticles by pulsed laser ablation technique. Appl Phys A 79(8):2099-2102

$\mathrm{LiGe}_{2}\left(\mathrm{PO}_{4}\right)_{3}$-JCPDS powder diffraction file, card no. 80-1922. Joint Committee on Powder diffraction Standards (JCPDS), Swarthmore

Mc Crum NG, Read BE, Williams G (1967) Anelastic and dielectric effects in polymeric solids. Wiley, New York

Milankovic AM, Furic K, Day DE (1997) Raman studies of PbO$\mathrm{Bi}_{2} \mathrm{O}_{3}-\mathrm{Ga}_{2} \mathrm{O}_{3}$ glasses and crystallized compositions. Phys Chem Glasses 38:148-150

Moynihan CT (1994) Analysis of electrical relaxation in glasses and melts with large concentrations of mobile ions. J Non-Cryst Solids 172-174:1395-1407 
Moynihan CT, Boesch LP, Laberge NL (1973) Decay function for the electric field relaxation in vitreous ionic conductors. Phys Chem Glasses 14:122-125

Nobre MAL, Lafendri S (2001) Phase transition in sodium lithium niobate polycrystal: an overview based on impedance spectroscopy. J Phys Chem Solids 21:999

Ohlbeg SM, Stricklet DW (1962) Effects of composition changes on the crystallization behavior and properties of $\mathrm{SiO}_{2}-\mathrm{Al}_{2} \mathrm{O}_{3}-\mathrm{CaO}-$ $\mathrm{MgO}\left(\mathrm{Fe}_{2} \mathrm{O}_{3}-\mathrm{Na}_{2} \mathrm{O}-\mathrm{K}_{2} \mathrm{O}\right)$. J Am Ceram Soc 45:170-172

Panmand RP, Kawade UV, Kulkarni MV, Apte SK, Kale BB, Gosavi SW (2010) Synthesis and characterization of $\mathrm{Bi}_{2} \mathrm{~S}_{3}$ nanosrystals in glass matrix. Mater Sci Eng B 168:161

Prasad SVGVA, Bhaskaran GS, Veeraiah N (2005) Spectroscopic, magnetic and dielectric investigations of $\mathrm{BaO}-\mathrm{Ga}_{2} \mathrm{O}_{3}-\mathrm{P}_{2} \mathrm{O}_{5}$ glasses doped by $\mathrm{Cu}$ ions. Phys Sta Soli A 202:2812-2828

Raghavan MS, Rao KJSL (1996) Electrical transport studies in alkali borovanadate glasses. J Phys Chem 100:4243

Reddy CKK, Balaji Rao R, Koti Reddy CV (2012) Influence of nanocrystalline phases on the electrical properties of lithium titanate phosphate glassceramics mixed with $\mathrm{Ga}_{2} \mathrm{O}_{3}$ nanocrystals. J Phase Transit 85:218

Reddy CKK, Balaji Rao R, Gopal Reddy C (2015) The role of crystallization on microstructural and electrical studies of lithium germanium phosphate glass-ceramic electrolytes. Ionics 21:967-979

Sambasiva Rao K, Murali Krishna P, Swarna Latha T, Madhava Prasad D (2008) Impedance spectroscopy analysis and piezoelectric properties of $\mathrm{Pb} 2 \mathrm{KNb} 5 \mathrm{O} 5$ ceramics. Mater Sci Eng B 131(1): 127

Sinclair DC, West AR (1989) Impedance and modulus spectroscopy of $\mathrm{BaTiO}_{3}$ showing positive temperature coefficient of resistance. J Appl Phys 66:3850-3856

Sinclair DC, West AR (1997) Characterization of electrical materials, especially ferroelectrics, by impedance spectroscopy. J Electroceram 1(1):65-71

Verhoef AH, den Hartog HW (1994) High frequency dielectric properties of alkali and alkali-halide borate glasses. Solid State Ionics 68:305

Xiaoxiong XU, Zhaoyin W, Xuelin Y, Gu Z (2006) Ionic conductivity and microstructural evaluton of $\mathrm{Li}_{2} \mathrm{O}-\mathrm{TiO}_{2}-\mathrm{P}_{2} \mathrm{O}_{5}-\mathrm{SiO}_{2}$ glass ceramics. Solid State Ionics 177:2611

$\mathrm{Xu} \mathrm{H}$, Gao L (2004) Hydrothermal synthesis of high purity $\mathrm{BaTiO}_{3}$ powders: control of powder phase and size, sintering density and dielectric properties. Mater Lett 58:1582-1586 